\title{
Endoscopic mucosal resection: The new gold standard or the "Bitcoin" of the present
}

\author{
Mark D. Iannettoni, MD, MBA
}

\footnotetext{
From the Division of Thoracic and Foregut Surgery, Department of Cardiovascular Sciences, East Carolina Heart Institute, Brody School of Medicine, East Carolina University, Greenville, NC. Disclosures: Author has nothing to disclose with regard to commercial support.

Received for publication Dec 24, 2017; accepted for publication Dec 28, 2017; available ahead of print Feb 1, 2017.

Address for reprints: Mark D. Iannettoni, MD, MBA, East Carolina Heart Institute, ECU, Vidant Medical Center, 115 Heart Drive, Room 3107, Greenville, NC 27834 (E-mail: iannettonim14@ecu.edu). J Thorac Cardiovasc Surg 2018;155:2219-20 $0022-5223 / \$ 36.00$

Copyright (c) 2018 by The American Association for Thoracic Surgery https://doi.org/10.1016/j.jtcvs.2017.12.094
}

When does a tool become a therapy? The article by Marino and colleagues, "Esophagectomy versus endoscopic resection for patients with early-stage esophageal adenocarcinoma: a national cancer database propensity-matched study," evaluating endoscopic mucosal resection (EMR) as an alternative to esophagectomy for the treatment of early esophageal cancer, provides yet another opportunity to ask the question "What is the current gold standard for the treatment for early-stage adenocarcinoma of the esophagus?",

The article attempts to answer this question using survival as the end point. It raises a number of issues related to our ability to successfully answer these questions with our current database-mining techniques. Although the ultimate outcome is survival, the detailed issues of patient selection and randomization, quality of life, postprocedural complications, types of procedures chosen in both groups, and crossover from the EMR to surgery remain unanswered.

The study demonstrates that initial survival is better with EMR, but long-term survival is better with esophagectomy. Is this initial benefit due to patient selection, operative technique, institutional expertise, or the lack of adequate preprocedural data, which may have affected outcomes? ${ }^{2}$ More important is the long-term benefit of esophagectomy related to improper follow-up of patients who undergo EMR, improper use of EMR, or selection of patients who were denied esophagectomy in the first place and outlived their therapy. Unfortunately, we will never know because of the missing data from these types of database reports.

Another important issue with respect to the EMR data is that we do not know exactly what procedure was done: Were these mucosal resections or submucosal resections, the latter of which is the preferred method because of better diagnostic and therapeutic results. ${ }^{3}$ We do not know the follow-up of these patients with further resections, the level of surveillance after the procedure, or the long-term complications of these patients. Also, the details of the pathology specimens, one of the most important criteria for deciding like a nail. physics. of care.

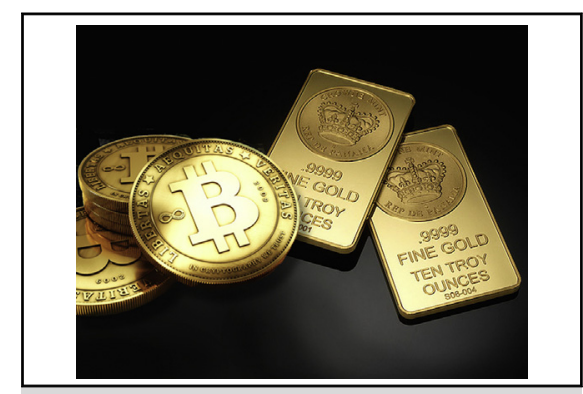

EMR versus esophagectomy: With so many unanswered questions, is it time to change the standard?

\section{Central Message}

The use of EMR as treatment for esophageal cancer rather than esophagectomy remains an acceptable alternative for early disease with major caveats for patients.

See Article page 2211.

which pathway to follow, are lacking in the study. It is important to know how many patients converted from the EMR group to the esophagectomy group because of higher stage after EMR than originally thought or those who came back for esophagectomy after EMR for recurrent disease at some point. We do know that these patients do just as well in some cases with proper follow-up even with a recurrence. ${ }^{4}$

One thing is clearly demonstrated by this study and review of the literature, and that is thoracic surgeons must be involved with these new techniques to allow for the patient to obtain the complete gamut of care when appropriate. If you can only perform EMR or only an esophagectomy, it is your only hammer, and consequently everything looks

This article also demonstrates an important aspect of participating in meta-analysis studies, and that is a level of attention to detail and being compulsive. In addition, complete data collection is an absolute to allow clinical equipoise in determining a new gold standard; otherwise, meta-analysis is to analysis as to what metaphysics is to

Although new and exciting, the technique of EMR remains to be accepted as the new standard and may be adopted by many as the current gold standard (including our group); however, until the lingering missing data points are provided, in my opinion it remains the Bitcoin 


\section{References}

1. Marino KA, Sullivan JL, Weksler B. Esophagectomy versus endoscopic resection for patients with early-stage esophageal adenocarcinoma: a National Cancer Database propensity-matched study. J Thorac Cardiovasc Surg. 2018;155:2211-8.e1. 2. Newton AD, Predina JD, Xia L, Roses RE, Karakousis GC, Dempsey DT, et al. Surgical management of early-stage esophageal adenocarcinoma based on lymph node metastasis risk. Ann Surg Oncol. 2018;25:318-25.
3. Nishizawa T, Yahagi N. Endoscopic mucosal resection and endoscopic submucosal dissection: technique and new directions. Curr Opin Gastroenterol. 2017;33: 315-9.

4. Wang S, Huang Y, Xie J, Zhuge L, Shao L, Xiang J, et al. Does delayed esophagectomy after endoscopic resection affect outcomes in patients with stage T1 esophageal cancer? A propensity score-based analysis. Surg Endosc. September 15, 2017 [Epub ahead of print]. 